\title{
HONEYBEES LEARN PATTERNS WITH FLASHING LIGHTS
}

\author{
SARA PERUFFO ${ }^{1}$, ELISABETTA VERSACE ${ }^{* 1,2}$, BETTINA MACCAGNANI ${ }^{2}$, and \\ GIORGIO VALLORTIGARA ${ }^{2}$ \\ *CORRESPONDING AUTHOR: E.VERSACE@QMUL.AC.UK \\ ${ }^{1}$ Center for Mind/Brain Sciences, University of Trento, Rovereto, Italy \\ ${ }^{2}$ Department of Biological and Experimental Psychology, \\ Queen Mary University of London, UK
}

\section{Introduction}

From linguistic stimuli to spatial and causal relations, extracting regularities is necessary to make sense of stimuli available in the world. Abilities to process abstract regularities have been observed across different species of mammals (Endress, Carden, Versace, \& Hauser, 2010; Murphy, Mondragón, \& Murphy, 2008) and birds (Spierings \& ten Cate, 2016; Versace, Regolin, \& Vallortigara, 2006; Versace, Spierings, Caffini, ten Cate, \& Vallortigara, 2017). An open question is whether insects exhibit pattern learning abilities. Honeybees are an ideal candidate to address this issue because they exchange with conspecifics complex information through the honeybee dance, and master abstract concepts such as "same" and "different" (Giurfa, Zhang, Jenett, Menzel, \& Srinivasan, 2001). Little is known, though, on their capacities to extract patterns from serially presented stimuli. Here we investigate the capacities of the honeybee Apis mellifera to extract temporal patterns by discriminating between lights presented with different rhythms. We trained foragers to gain a sucrose reward by choosing a flashing $v s$. a static light and documented honeybees' capacity to solve this discrimination task.

\section{Methods}

Individually marked bees (Apis mellifera) were trained to run through a Y-maze to collect 50\% (weight/weight) sucrose solution. The apparatus, covered with a transparent net, was located in front of a window and illuminated by daylight. Bees 
entered the apparatus through the open window and found at the end of the corridor two blue circles ( $6 \mathrm{~cm}$ diameter) illuminated by LED lightbulbs, one on the right and one on the left branch (see Fig. 1). One stimulus was illuminated by a static light, the other by a flashing light. For each subject, only the flashing (static) stimulus was rewarded with sucrose solution, while the other stimulus was baited with a bitter, quinine solution. The position of the rewarded stimulus was randomized between trials.

Figure 1. Overhead view of the apparatus.

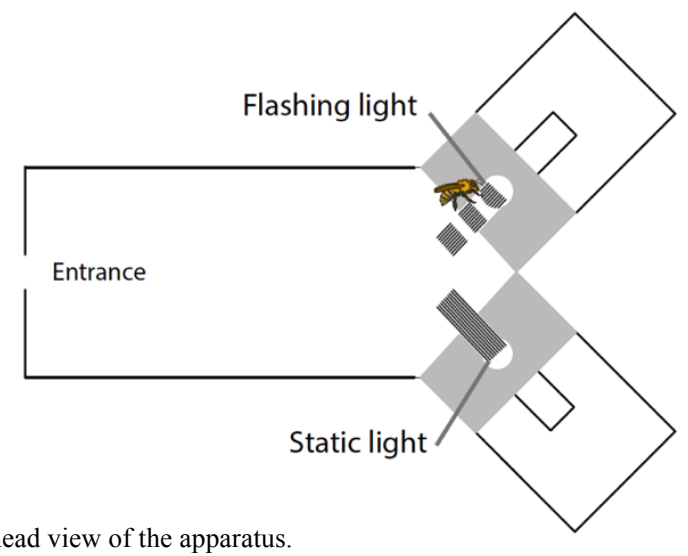

We analyzed the individual and overall performance of bees that made a choice in the apparatus at least 24 times, using a two-tailed binomial test for individual performance, and a two-tailed one-sample Mann-Whitney test against the chance level for the overall performance.

\section{Results and discussion}

Seven bees made at least 24 choices in the apparatus. Four out of seven bees reached a performance significantly different from chance (18 or more correct responses: $21 / 24,87.5 \%, \mathrm{p}<0.001 ; 20 / 24,83 \% \mathrm{p}<0.01 ; 18 / 24,75 \%, \mathrm{p}=0.023$; $18 / 24,75 \%, p=0.023)$, while three bees did not $(17 / 24,71 \%, p=0.064 ; 14 / 24$, $58 \%, \mathrm{p}=0.541 ; 10 / 24,42 \%, \mathrm{p}=0.541)$. All bees with a significant performance chose the rewarded stimulus. Overall, we observed a significant preference for the rewarded stimulus $(\mathrm{V}=27, \mathrm{p}=0.034)$, in fact all bees except one choose the rewarded pattern more often than the other one. These results suggest that honeybees can discriminate between static and flashing lights and that these insects are a suitable model for further investigation of artificial grammar learning. To the best of our knowledge, this is the first example of temporal pattern learning documented in honeybees. Insects can shed light into the evolution of pattern learning that does not depend on language. 


\section{References}

Endress, A. D., Carden, S., Versace, E., \& Hauser, M. D. (2010). The apes' edge: positional learning in chimpanzees and humans. Animal Cognition, 13(3), 483-95. https://doi.org/10.1007/s10071-009-0299-8

Giurfa, M., Zhang, S., Jenett, A., Menzel, R., \& Srinivasan, M. V. (2001). The concepts of "sameness" and "difference" in an insect. Nature, 410(6831), 930-933. https://doi.org/10.1038/35073582

Murphy, R. A., Mondragón, E., \& Murphy, V. A. (2008). Rule learning by rats. Science, 319(5871), 1849-51. https://doi.org/10.1126/science.1151564

Spierings, M. J., \& ten Cate, C. (2016). Budgerigars and zebra finches differ in how they generalize in an artificial grammar learning experiment.

Proceedings of the National Academy of Sciences, 3977-3984.

https://doi.org/10.1073/pnas.1600483113

Versace, E., Regolin, L., \& Vallortigara, G. (2006). Emergence of Grammar as Revealed by Visual Imprinting in Newly-hatched Chicks. In: The Evolution of Language. In Proceedings of the 6th International Conference, Rome, 12-15 April 2006.

Versace, E., Spierings, M. J., Caffini, M., ten Cate, C., \& Vallortigara, G. (2017). Spontaneous generalization of abstract multimodal patterns in young domestic chicks. Animal Cognition. https://doi.org/DOI 10.1007/s10071-017-1079-5 